\title{
In vivo Effects of Di-n-butyl Phthalate and Di-2-ethylhexyl Phthalate on the Nonspecific Defense Mechanism of the Bagrid Catfish, Pseudobagrus fulvidraco
}

\author{
Fatima Masroor ${ }^{1}$, Jung-Hoon Jee ${ }^{2}$, Yoo-Hwa Keum ${ }^{3}$ and Ju-Chan Kang ${ }^{3}$ \\ ${ }^{1}$ Department of Biology, University of Namur, Belgium \\ ${ }^{2}$ Trade Promotion Division, International Cooperation Bureau, Ministry of Maritime Affairs \\ \& Fisheries, Seoul 110-793, Korea \\ ${ }^{3}$ Department of Aquatic Life Medicine, Pukyong National University, Busan 608-737, Korea
}

\begin{abstract}
The aim of this study was to investigate in vivo toxicity and effects of two phthalate esters (PEs), di- $n$-butylphthalate (DBP) and di-2-ethylhexyl phthalate (DEHP), on the immune system of the bagrid catfish, Pseudobagrus fulvidraco. Groups of experimental fish were subjected to daily intraperitoneal injections of 300 or $1000 \mathrm{mg} \mathrm{kg}^{-1}$ of DBP or DEHP for 3 days, and the cellularity and functional activity of phagocytes were measured in the spleen and pronephros (head kidney). The number of spleen leukocyte cells increased significantly $(\mathrm{p}<0.05)$ in response to low and high doses of DEHP and DBP, respectively; however, the cellularity of the pronephros was more susceptible to higher dose of DEHP than DBP. Nonspecific immunity, as determined by the phagocytic index (PI) and phagocytic capacity (PC), was significantly depressed by DEHP at $1000 \mathrm{mg} \mathrm{kg}^{-1} \mathrm{day}^{-1}$ in the pronephros at 3 days after injection. Furthermore, significantly $(\mathrm{p}<0.05)$ increased levels of serum glutamic oxaloacetate transaminase (GOT) and glutamic pyruvate transaminase (GPT) indicated marked hepatic dysfunction in immunosuppressed fish. Treated fish showed a significant reduction in total serum protein but no significant alteration in lysozyme activity. These results demonstrate the sensitivity of the fish immune response for predicting PE-induced immunotoxicity.
\end{abstract}

Key words: Di- $n$-butyl phthalate, Di-2-ethylhexyl phthalate, Nonspecific defense mechanism, Pseudobagrus fulvidraco

\section{Introduction}

Phthalate esters (PEs) are a group of organic chemicals used as plasticizers to increase the flexibility and durability of plastics. More than 4 million tons of PEs are produced worldwide each year (Furtman, 1996), making them some of the most highly produced and commercially significant synthetic chemicals in the world. The commercial PEs di- $n$-butyl phthalate (DBP) and di-2-ethylhexyl phthalate (DEHP) have different industrial use scenarios. Reports are available on their occurrence in industrial waste waters, rivers, fish, and other aquatic organisms (Scholz et al., 1997; Sonnenschein and Soto, 1998; Roger et al., 2002; Chang et al., 2005).

The frequency of human and animal exposure to

\footnotetext{
*Corresponding author: jckang@pknu.ac.kr
}

these compounds and their toxic potential for human and animal reproduction have resulted in studies of their environmental distribution, bioaccumulation, fate, and mechanisms of action (Staples et al., 1997; Kim et al., 2002). Moreover, these esters are also suspected endocrine disruptors and estrogen mimic compounds (Sonnenschein and Soto, 1998; Shioda and Wakabayashi, 2000; Tollefsen, 2002). As phthalic acid-derived compounds, PEs have been shown to induce estrogen receptor-mediated responses (Jobling et al., 1995). Stress caused by environmental variables can affect the endocrine system, which in turn, through bi-directional communication, can affect other intimately linked systems, such as the immune and nervous systems, to maintain homeostasis (Balm, 1997). Therefore, concern exists that PEs in waterways may be causing adverse effects on fish immune systems and consequently on fish health. 
In vitro exposure tests have been conducted by Hironobu et al. (2003) and Sung et al. (2003) to evaluate the xenoestrogenic potency and immunotoxicity of DBP and DEHP in fish and prawns. However, according to Van den Belt et al. (2004), the actual relative estrogenic potency would be about 25 times that expected based on in vitro results. Thus, further investigation is warranted, including in vivo studies to screen for potential effects of well-known estrogen-mimicking phthalate esters on fish immune systems.

The present in vivo study was conducted to quantify the sensitivity of the fish immune response and to further observe the relative debilitating effects of DBP and DEHP on nonspecific resistance factors of the freshwater bagrid catfish (Pseudobagrus fulvidraco) under laboratory conditions. Serum total protein, glutamic oxaloacetate transaminase (GOT), and glutamic pyruvate transaminase (GPT) levels were measured as indicators of disturbed metabolic functions.

\section{Experimental fish}

Materials and Methods

Bagrid catfish, Pseudobagrus fulvidraco, were obtained from the Inland Fisheries Research Institute, Chungbuk, Korea, and were housed in 80-L freshwater flow-through system tanks (water exchange rate, $9 \mathrm{~L} / \mathrm{h}$ ) in the Aquatic Life Medicine Laboratory of Pukyong National University. The physico-chemical characteristics of the tank water are presented in Table 1. The tanks were housed under controlled conditions at $22-23^{\circ} \mathrm{C}$ and with a photoperiod of $15: 9$ h, light:dark. Each tank was stocked with ten fish (mean weight, $40.78 \pm 1.39 \mathrm{~g}$ ) of mixed gender. The fish were fed daily with a commercial diet feed (Woosung Co., Korea) and were acclimatized to the experimental conditions for 3 weeks to reduce stress-

Table 1. Physico-chemical properties of water during experimental period

\begin{tabular}{lc}
\hline Parameters & Values \\
\hline Temperature $\left({ }^{\circ} \mathrm{C}\right)$ & $22.3 \pm 0.8$ \\
$\mathrm{pH}$ & $7.24 \pm 0.46$ \\
$\mathrm{NH}_{4}-\mathrm{N}(\mu \mathrm{g}-\mathrm{at} / \mathrm{L})$ & $8.54 \pm 0.64$ \\
$\mathrm{NO}_{2}-\mathrm{N}(\mu \mathrm{g}-\mathrm{at} / \mathrm{L})$ & $1.46 \pm 0.21$ \\
$\mathrm{NO}_{3}-\mathrm{N}(\mu \mathrm{g}-\mathrm{at} / \mathrm{L})$ & $7.45 \pm 0.65$ \\
$\mathrm{PO}_{4} \mathrm{P}(\mu \mathrm{g}$-at/L) & $4.56 \pm 0.39$ \\
$\mathrm{SS}(\mathrm{mg} / \mathrm{L})$ & $3.65 \pm 0.29$ \\
Dissolved oxygen $(\mathrm{mg} / \mathrm{L})$ & $6.73 \pm 0.53$ \\
Hardness $(\mathrm{mg} / \mathrm{L})$ & $231.7 \pm 5.7$ \\
\hline
\end{tabular}

Values indicate mean $\pm \mathrm{SE}(\mathrm{n}=8)$, two times/day. related responses.

\section{Chemical preparation and administration}

Di- $n$-butylphhalate (DBP) and di-2-ethylhexyl phthalate (DEHP) were obtained from Sigma (St. Louis, MO, USA). Stock solutions were prepared in sunflower seed oil. Fish were randomly distributed into five groups. Group A was the control; groups B1 and $\mathrm{B} 2$ received injections of 300 and $1,000 \mathrm{mg} / \mathrm{kg}$ body weight (bw) DBP respectively; groups D1 and D2 received the same respective doses of DEHP. Owing to the hydrophobicity of these chemicals, intraperitoneal injection (i.p.) was used to provide a more effective dosing route for evaluating true systematic toxicity. To simulate environmental exposure under laboratory conditions, the fish in the four experimental groups were administered DBP and DEHP in a volume of around $50 \mu \mathrm{L}(1 \mathrm{~mL} / \mathrm{kg} \mathrm{bw})$ of sunflower seed oil as a carrier, via a daily i.p. injection for 3 consecutive days, using a tuberculin syringe with a 23 -gauge needle. In each treatment tank, ten fish were injected with the assigned dosages. The control, group A, received an injection of an equal volume of sunflower seed oil following the same schedule.

Fish length and weight were measured at the time of injection and at the time of termination. Fish and water quality were monitored daily up to the day the experiment was terminated to assess chemical-induced changes in host mortality and behavior (i.e., erratic swimming, hyperactivity, lack of feeding). The fish remained healthy based on the absence of infection, disease, and mortality.

Five fish per control and each treatment group were anesthetized with 3-aminobenzoic acid ethyl ester methanesulfonate (Sigma) following the cessation of dosing (day 4). Blood was collected from each fish by puncturing the caudal vessel using an unheparinized syringe, and the blood was allowed to coagulate at room temperature for $2 \mathrm{~h}$. The serum was obtained by centrifugation and was stored at $-80^{\circ} \mathrm{C}$ until analyzed.

\section{Lymphoid organ weights}

After the collection of blood, the spleen and the pronephros (head kidney) were isolated from each fish and were placed in separate culture dishes containing $1 \mathrm{~mL}$ of ice-cold Leibovitz's L-15 medium (L-15, pH 7.2). The weights of the lymphoid organs (spleen and pronephros) were recorded for each group after the termination of the experiment. The relative organ weights were calculated for each animal following the method of Fatima et al. (2001). 


\section{Isolation of leucocytes}

The leucocytes were isolated from the spleen and pronephros using a modification of the method described in Fatima et al. (2001). Single-cell suspensions were prepared by dissociating the lymphoid tissues, using a cell dissociation sieve-tissue grinder kit (Sigma), in L-15 medium supplemented with $0.1 \%$ fetal bovine serum (FBS), $1 \%$ streptomycin/ penicillin solution (S/P, Gibco, USA), and $10 \mathrm{U} / \mathrm{mL}$ heparin (Sigma). The resulting suspensions were purified in Percoll (Sigma) density gradients (34/ $51 \%$ ) centrifuged at $400 \times \mathrm{g}$ at $4^{\circ} \mathrm{C}$ for $30 \mathrm{~min}$, and the band of cells at the interface was harvested into siliconized tubes.

\section{Lymphoid organ cellularity}

The cells collected from the interface were washed twice by centrifugation $\left(1,000 \times \mathrm{g}\right.$ at $4^{\circ} \mathrm{C}$ for $\left.10 \mathrm{~min}\right)$ in non-supplemented L-15 medium. The final cell pellet was resuspended in $1 \mathrm{~mL}$ of $\mathrm{L}-15$ medium $(\mathrm{pH}$ 7.2) supplemented with $0.1 \%$ FBS, $1 \% \mathrm{~S} / \mathrm{P}$ (Gibco), and $10 \mathrm{U} / \mathrm{mL}$ heparin (Sigma). Cells were counted using a hemocytometer. Cell viability was determined using the trypan blue dye exclusion method. The number of cells was expressed in millions per $\mathrm{mL}$. Differential counts were performed to assess the population of leukocytes in the spleen and pronephros cell suspensions. Cell numbers were adjusted to achieve the desired concentration $\left(1 \times 10^{7}\right.$ leukocytes $/ \mathrm{mL}$ ) for the particular assays.

\section{Assay of phagocytic activity}

Phagocytic activity was evaluated using a cell suspension, as described in Ahmad et al. (1998). An aliquot of $0.1 \mathrm{~mL}$ with a cell density of $1 \times 10^{7}$ cells/ $\mathrm{mL}$ in L-15 medium was mixed with an equal volume of L-15 medium containing $20 \%$ FBS and $1 \times 10^{8}$ cells $/ \mathrm{mL}$ of heat-treated $\left(100^{\circ} \mathrm{C}\right.$ for $\left.1 \mathrm{~h}\right)$ yeast cells (Saccharomyces cerevisciae). Phagocytosis was allowed to proceed for $1 \mathrm{~h}$ at $35^{\circ} \mathrm{C}$ with occasional shaking. After incubation, $50 \mu \mathrm{L}$ of this mixture was smeared onto glass slides, air dried, fixed in methanol, and stained with Diff-Quik solution (Japan). The slides were air dried and observed under Malinol (MPC, Japan). The average number of yeast cells engulfed per phagocyte was determined by inspecting 500 phagocytic cells from each sample. Phagocytic activity was expressed using the phagocytic index (PI) and as a percentage of phagocytic capacity (PC). The phagocytic index was calculated as:

$$
\mathrm{PI}=\mathrm{A} \times \mathrm{B}
$$

where $\mathrm{A}=$ the percentage of phagocytes engulfing at least two yeast cells, and $\mathrm{B}=$ the average number of yeast cells engulfed by phagocytosis-positive cells.

\section{Serum analysis}

The lysozyme assay was performed according to Ellis (1990), with some modifications. First, $0.2 \mathrm{mg} /$ $\mathrm{mL}$ Micrococcus lysodeikticus (Sigma) was suspended in $0.05 \mathrm{M}$ sodium phosphate buffer, $\mathrm{pH}$ 6.2. Then, $50 \mu \mathrm{L}$ of serum were added to $950 \mu \mathrm{L}$ of the bacterial suspension, and the absorbance at $450 \mathrm{~nm}$ was measured at 30 -s intervals for $3 \mathrm{~min}$ at $25^{\circ} \mathrm{C}$. One unit (U) of lysozyme activity was defined as the amount of sample causing a reduction in absorbance of $0.001 \mathrm{~min}^{-1}$. The total protein estimation and the glutamic oxaloacetate transaminase (GOT) and glutamic pyruvate transaminase (GPT) assays were performed using a diagnostic kit and reagent supplied by Asan Pharm. Co., Ltd, Korea.

\section{Statistical analysis}

The data were analyzed using a one-way analysis of variance (ANOVA) to observe the treatment effects. Duncan's multiple range test was used to evaluate the significant differences between groups. Differences were considered statistically significant at $p<0.05$.

\section{Results}

\section{Influence of phthalates on lymphoid organ weights}

Table 2 summarizes the effect of phthalates on the relative lymphoid organ weights. No toxicant-induced changes in body weight or relative lymphoid organ weights were found in the toxicity test. There were no significant differences in the weights of lymphoid organs between the control and treated fish groups. Although the relative spleen weight increased in the group treated with $300 \mathrm{mg} \mathrm{DBP} \mathrm{kg}^{-1} \mathrm{bw}$, the increase was not significant at $\mathrm{p}<0.05$.

Table 2. Effect of phthalate esters exposure on relative lymphoid organ weights of bagrid catfish, Pseudobagrus fulvidraco

\begin{tabular}{lcccc}
\hline & \multirow{2}{*}{$\begin{array}{c}\text { Body } \\
\text { Weight }\end{array}$} & \multicolumn{2}{c}{$\begin{array}{c}\text { Organ weight / body weight } \\
\times 100\end{array}$} \\
\cline { 4 - 5 } & & $(\mathrm{g})$ & Spleen & Pronephros \\
\hline Control & 5 & 43.90 & $0.106 \pm 0.015$ & $0.138 \pm 0.019$ \\
DBP-300 mg/kg & 5 & 37.27 & $0.132 \pm 0.015$ & $0.326 \pm 0.156$ \\
DBP-1000 mg/kg & 5 & 39.29 & $0.104 \pm 0.013$ & $0.129 \pm 0.016$ \\
DEHP-300 mg/kg & 5 & 42.70 & $0.141 \pm 0.037$ & $0.157 \pm 0.015$ \\
DEHP-1,000 mg/kg & 5 & 40.72 & $0.103 \pm 0.018$ & $0.171 \pm 0.024$
\end{tabular}

Results are presented as the mean $\pm \mathrm{SE}$ of five fish per group. Values were not significantly different from control group at $\mathrm{p}<0.05$. 


\section{Effects on splenic and pronephric cellularity}

The total numbers of single cells in the spleen and pronephros following i.p. administration of the two phthalates are shown in Fig. $1 \mathrm{~A}$ and $\mathrm{B}$, respectively. The number of splenocytes significantly increased with $1,000 \mathrm{mg}$ DBP $\mathrm{kg}^{-1}$ and $300 \mathrm{mg}$ DEHP kg-1 bw compared with the control group $(\mathrm{p}<0.05)$. Moreover, higher doses of DEHP resulted in a greater number of leukocytes in the pronephros relative to the control group $(p<0.05)$ as well as to most of the other treat-
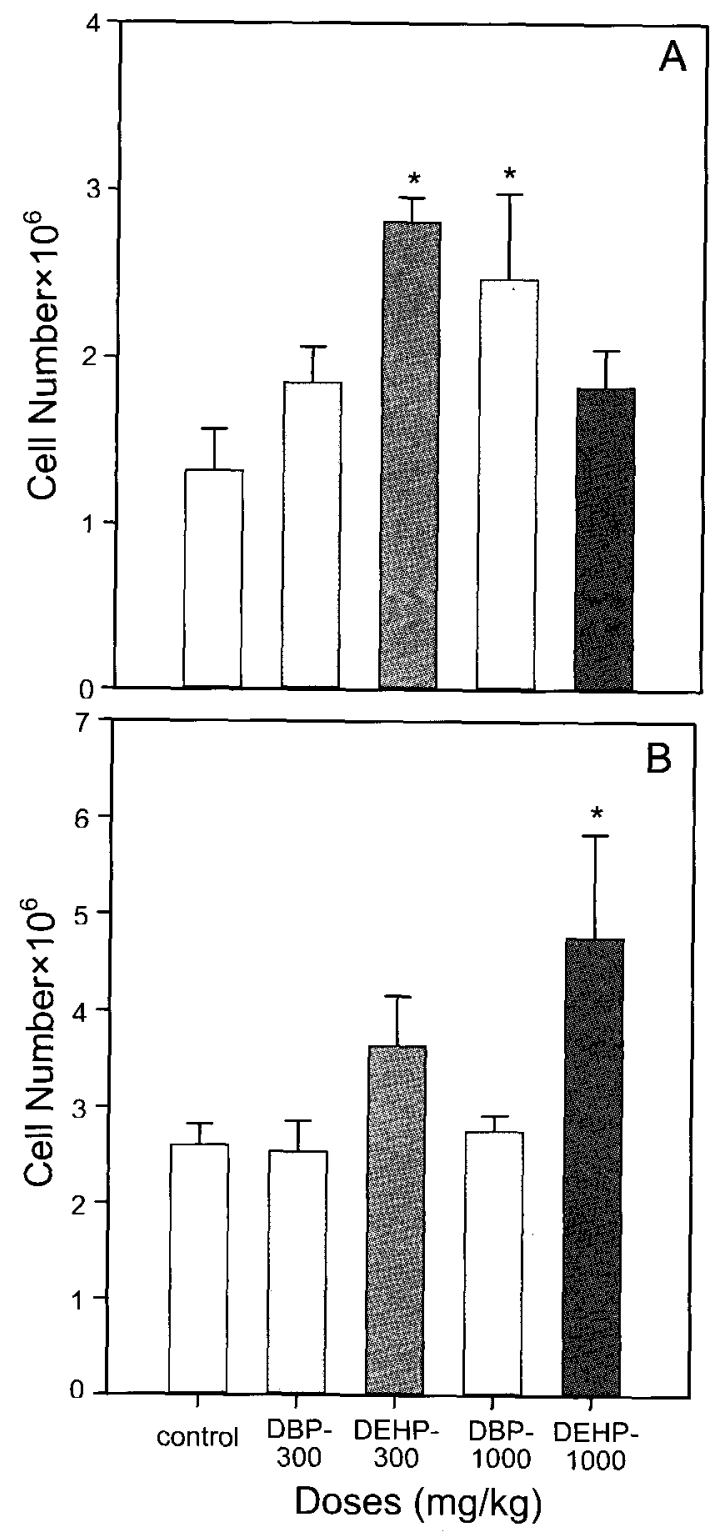

Fig. 1. Effect of DBP and DEHP exposure on mean cellularity of the spleen (A) and pronephros (B). Error bars represent mean \pm S.E. of five fish per treatment group. ${ }^{*} \mathrm{p}<0.05$ vs. vehicle control group. ment groups. No significant difference was observed in the cell number of the pronephros between DBPtreated and untreated fish.

\section{Phagocytic functional responses of leukocytes}

The dose-dependent effects on the nonspecific immune response and the phagocytic effects of DBP and DEHP in bagrid catfish are illustrated in Figs. $2 \mathrm{~A}$ and $\mathrm{B}$ and $3 \mathrm{~A}$ and $\mathrm{B}$. Exposure to $300 \mathrm{mg} \mathrm{DBP} \mathrm{kg} \mathrm{mb}^{-1} \mathrm{bw}$ markedly increased the nonspecific immunity of fish, as indicated by the elevated PI $(p<0.05)$ in the spleen

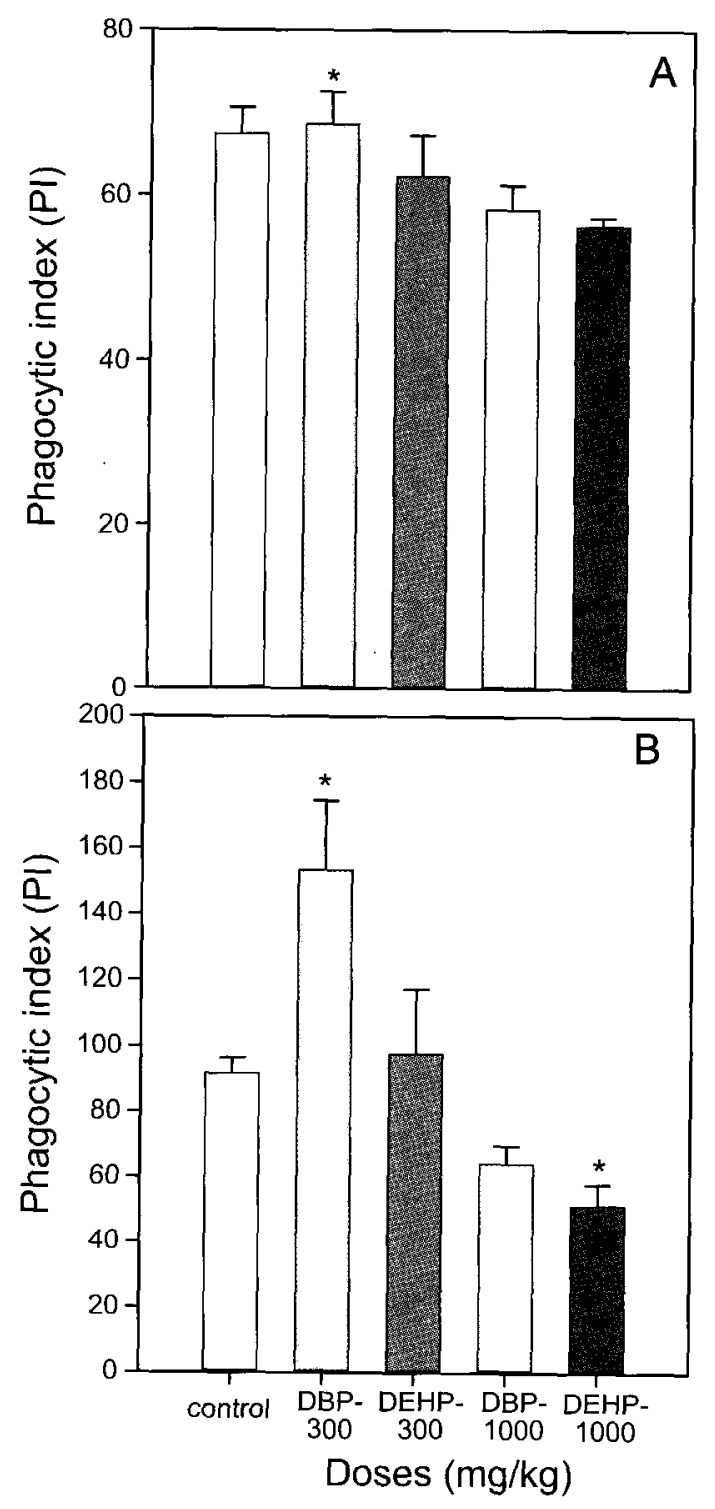

Fig. 2. Effect of DBP and DEHP exposure on phagocytic index (PI) of fish phagocytes isolated from spleen (A) and pronephros (B). Error bars represent mean \pm S.E. of five fish per treatment group. ${ }^{*} p<0.05$ represent significant differences over control fish. 
(Fig. 2A) and pronephros (Fig. 2B). In contrast, exposure to $1,000 \mathrm{mg} \mathrm{DEHP} / \mathrm{kg}$ bw significantly $(\mathrm{p}<0.05)$ decreased the PI of leucocytes isolated from the pronephros (Fig. 2B). Furthermore, the phagocytic efficiency differed $(p<0.05)$ between control and treatment groups, with a reduction in capacity, especially in pronephros macrophages, under the acute stress of treatment with $1,000 \mathrm{mg}$ DEHP or DBP $\mathrm{kg}^{-1} \mathrm{bw}$, indicating the immunosuppressive
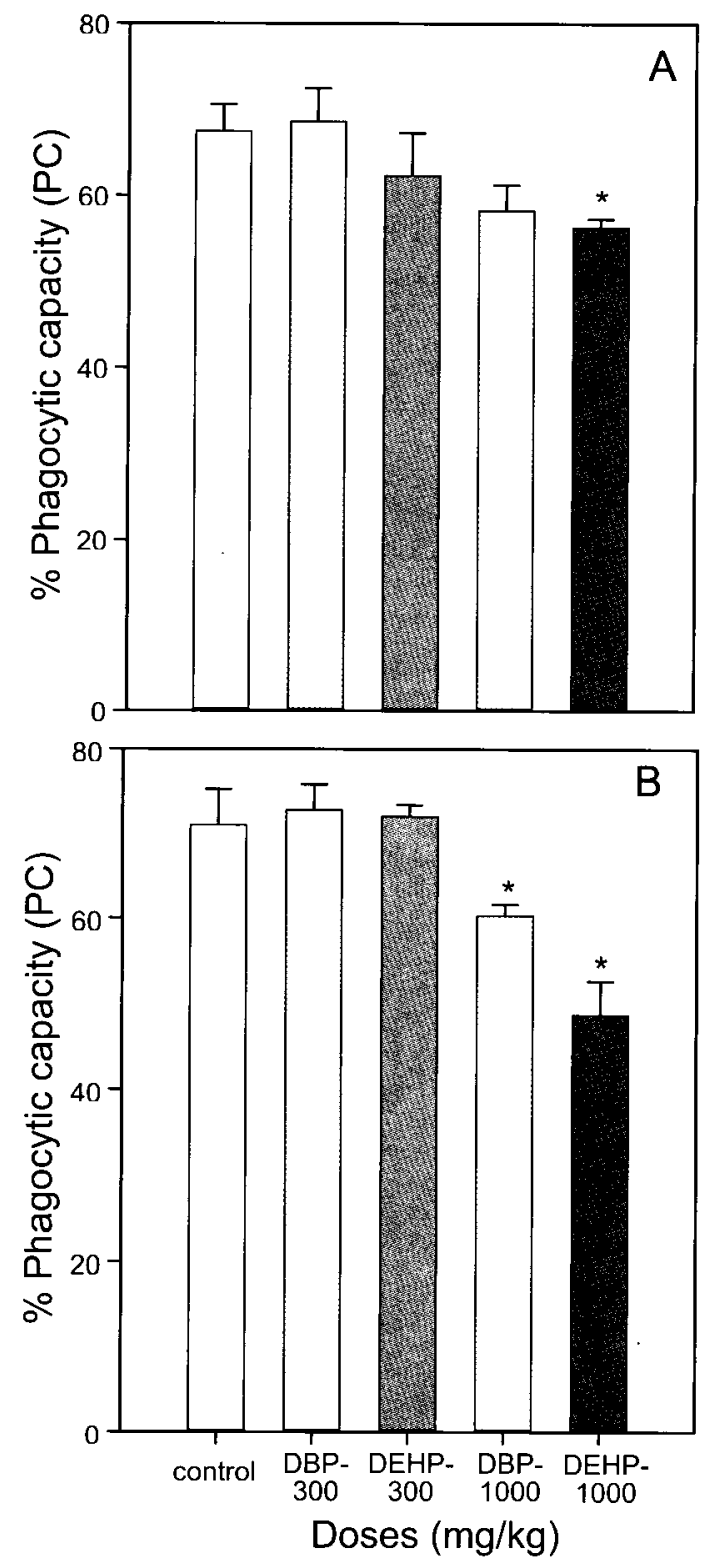

Fig. 3. Phagocytic capacity (PC) of fish phagocytes isolated from spleen (A) and pronephros (B) of bagrid catfish after i.p. exposure to DBP and DEHP. Error bars represent mean \pm S.E. of five fish per treatment group. ${ }^{*} \mathrm{p}<0.05$ vs. vehicle control group. nature of phthalate esters (Fig. 3B). The higher treatment dose of DEHP $(1,000 \mathrm{mg} / \mathrm{kg} \mathrm{bw})$ inhibited the phagocytic capacity of splenocytes $(p<0.05$; Fig. $3 \mathrm{~A})$.

\section{Lysozyme activity}

The phthalate esters decreased the serum lysozyme activity in bagrid catfish in a dose-dependent manner, but the activities in the treated groups were not significantly different from that in the carrier-injected control group (Table 3).

\section{Metabolic indicators}

The total protein, GOT, and GPT serum levels are presented in Table 3 . In all experimental groups, the total protein level was suppressed by phthalate esters in a dose-dependent manner $(\mathrm{p}<0.05)$. High levels of serum GOT were noted in the treated groups, and serum GOT in the fish exposed to $1,000 \mathrm{mg}$ DEHP was markedly higher than that in the control group $(\mathrm{p}<0.05$; Table 3$)$. The GPT activity in the groups treated with $1,000 \mathrm{mg}$ DBP or DEHP was higher than that in the control group $(\mathrm{p}<0.05$; Table 3$)$.

\section{Discussion}

Markers of nonspecific immunity appear to be successful indicators of xenobiotic-induced stress in laboratory fish. In recent years, considerable evidence has accumulated to support links between environmental changes (including contaminants), noninfectious diseases, and immune system depression (Zelikoff et al., 2000; Fatima et al., 2001). The total leukocyte number from fish hematopoietic organs is considered to be a more sensitive indicator of chemical toxicity than the activity of phagocytic cells contained within these organs (Hart et al., 1998). In the short period of the present toxicity test, neither DBP nor DEHP influenced the body weight or the relative weights of lymphoid organs, regardless of the organ and the exposure dose (Table 2). In lymphoid organs, low and high doses of DEHP and DBP, respectively, caused high cellularity in the spleen. The hypercellularity in the fish pronephros associated with the treatment of $1,000 \mathrm{mg} \mathrm{DEHP} / \mathrm{kg}$ bw is in agreement with the dose-dependent induction of thymocyte populations in mice by dioctyl phthalate (Dogra et al., 1993). Taken together, these results suggest remarkable, tissue-specific differences in induction of proliferation by phthalate esters. The present finding agrees with the results obtained by Sabourault et al. (1998) in sea bass treated with daily intra-peritoneal injections of $1.5 \mathrm{~g} \mathrm{DEHP} / \mathrm{kg}$ bw/day for 3 days. The DEHP-induced proliferation seen here 
Table 3. Effect of DBP and DEHP on serum lysozyme, total protein, GOT and GPT levels in exposed bagrid catfish

\begin{tabular}{|c|c|c|c|c|c|}
\hline \multirow{3}{*}{ Parameters } & \multicolumn{5}{|c|}{ Exposure groups } \\
\hline & \multirow{2}{*}{ Control } & \multicolumn{2}{|c|}{$\mathrm{DBP}(\mathrm{mg} \mathrm{DBP} / \mathrm{kg} \mathrm{bw})$} & \multicolumn{2}{|c|}{$\mathrm{DEHP}$ (mg DEHP/kg bw) } \\
\hline & & 300 & 1,000 & 300 & 1,000 \\
\hline Lysozyme activity (unit/mL) & $89.4 \pm 4.3$ & $88.6 \pm 3.8$ & $77.4 \pm 5.4$ & $84.2 \pm 4.5$ & $81.8 \pm 6.3$ \\
\hline Total protein $(\mathrm{g} / \mathrm{dL})$ & $5.15 \pm 0.12^{\mathrm{a}}$ & $3.91 \pm 0.29^{\mathrm{b}}$ & $3.88 \pm 0.15^{b}$ & $4.07 \pm 0.20^{\mathrm{b}}$ & $3.93 \pm 0.16^{\mathrm{b}}$ \\
\hline GOT (Karmen unit) & $47.74 \pm 2.38^{a}$ & $53.00 \pm 9.64^{a b}$ & $57.84 \pm 8.28^{a b}$ & $52.67 \pm 4.04^{a b}$ & $74.22 \pm 9.27^{b}$ \\
\hline GPT (Karmen unit) & $10.93 \pm 1.23^{\mathrm{a}}$ & $8.97 \pm 1.65^{\mathrm{a}}$ & $17.71 \pm 2.16^{b}$ & $10.46 \pm 1.93^{\mathrm{a}}$ & $18.91 \pm 1.79^{b}$ \\
\hline
\end{tabular}

Value are means $\pm \mathrm{SE}(\mathrm{n}=5)$. Different superscript are significantly different $(\mathrm{P}<0.05)$ as determined by Duncan's multiple range test. GOT: Glutamic oxaloacetate transaminase; GPT: Glutamic pyruvate transaminase.

in bagrid catfish may be similar to that to observed in mammals (Sabourault et al., 1999). According to Sabourault et al. (1999) in fish as well as rodents, DEHP induces peroxisome proliferation by increaseing the activity of microsomal lauric acid hydroxylase (LAH) in the kidney and, to a lesser extent, in the liver.

DBP and DEHP demonstrated immunomodulatory effects on the phagocytic efficiency of $P$. fulvidraco leukocytes that both elevated and suppressed nonspecific immune responses in our in vivo laboratory experiment. Low doses of DBP ( $300 \mathrm{mg} / \mathrm{kg} \mathrm{bw}$ ) had an immunostimulatory effect on the PI in the spleen and pronephros phagocytes. A significant reduction in the PI was observed in the pronephros at the higher DEHP concentration $(1,000 \mathrm{mg} / \mathrm{kg}$ bw). A dosedependent biphasic response has also been reported in fish treated with gonadal steroids (Wan-Yu et al., 2001; Yamaguchi et al., 2001).

Immunosuppressive effects, in terms of PC, were seen in the pronephros and spleen treated with the higher dose of DEHP. However, the higher DBP concentration also suppressed the PC of pronephros phagocytes.

In the present study, DEHP $(1,000 \mathrm{mg} / \mathrm{kg})$ particularly influenced the potential killing activity of pronephros leukocytes and contributed to the receptor binding ability of phthalate esters. Phthalate esters have been identified as xenoestrogenic compounds that mimic endogenous estrogens and exert direct effects on cells via estrogen receptors (Tollefsen, 2002). Hironobu et al. (2003) reported the expression of estrogen receptors in brain, liver, and fish kidney leucocytes. The present in vivo results revealed immunosuppression in exposed fish, especially in those treated with the high dose of DEHP. The reduction in nonspecific immune responses may be caused by the release of hormones such as cortisol, progesterone, and testosterone, leading to immuno suppressive effects through direct actions on leukocytes via androgen receptors (Slater et al., 1995; Yamaguchi et al., 2001). The low potential effects of DBP might have been related to its low affinity for estrogen receptors (Tollefsen, 2002) and the likelihood that the xenoestrogenic impact of a phthalate is directly related to estrogen receptor binding in pronephros leukocytes (Zacharewski et al., 1998).

The dose-dependent reduction in total serum protein and the immunomodulation by DBP and DEHP suggested a disturbed physiological mechanism and a specific, receptor-mediated induction by phthalate esters, respectively. The high rate of GOT and GPT activity in fish treated with $1,000 \mathrm{mg}$ DEHP indicated a greater degree of hepatic dys-function in immunosuppressed fish. The discrepancy between the immune responses of spleen and pronephros leukocytes might have resulted from toxicity differences and selective distribution patterns of phthalate esters in the organ tissues of fish, as suggested in Menghi et al. (2002).

The absence of an effect on lysozyme activity and the significantly elevated phagocytic index, particularly that obtained with low doses of DBP, in fish lymphoid organs implicated an immunostimulatory effect of straight-chain phthalate esters at low concentrations. Furthermore, the lack of significant changes in GOT and GPT also suggested normal hepatic function in fish treated with the low DBP concentration. Generally, in aquatic organisms, the toxicity of phthalate esters increases with increasing alkyl chain length (Parkerton and Konkel, 2000). Thus, the consistent differences in the results between DBP and DEHP treatments might be attributable to differences in their chemical structures.

The results of this in vivo study of the effects of DBP and DEHP in fish demonstrated that these chemicals are not only endocrine disruptors but also are responsible for the alteration of aquatic organism 
immunocompetency.

\section{References}

Ahmad, I., M. Fatima, M. Athar, N.Z. Khan and S. Raisuddin. 1998. Responses of circulating fish phagocytes to paper mill effluent exposure. Bull. Environ. Contam. Toxicol., 61, 746-753.

Balm, P.H.M. 1997. Immune-endocrine interactions. In: Fish Stress and Health in Aquaculture, Iwama, G.K., A.D. Pickering, J.P. Sumpter, C.B. Schreck, eds. Cambridge University Press, Cambridge, 195-221.

Chang, B.V., C.S. Liao and S.Y. Yuan. 2005. Anaerobic degradation of diethyl phthalate, di- $n$ butyl phthalate, and di-(2-ethyhexyl) phthalate from river sediment in Taiwan. Chemosphere, 58, 1601-1607.

Dogra, R.K., S. Khanna, S.N. Srivastava, L.J. Shukla, K. Chandra, G. Saxena and R. Shanker. 1993. Immunomodulation due to coexposure to styrene and dioctyl phthalate in mice. Immunopharmacol. Immunotoxicol., 15, 491-514.

Ellis, A.E. 1990. Lysozyme assays. In: Techniques in Fish Immunology Vol. I, Stolen, J.S., D.P. Anderson, B.S. Roberson and W.B. van Muiswinkel, eds. SOS Publications, New Haven, NJ, 101-103.

Fatima, M., I. Ahmad, R. Siddiqui and S. Raisuddin. 2001. Paper and pulp mill effluent-induced immunotoxicity in freshwater fish Channa punctatus (Bloch). Arch. Environ. Contam. Toxicol., 40, 271-276.

Furtman, K. 1996. ECPI European Council for Plasticisers \& Intermediates. Phthalates in the Aquatic Environment. Dusseldorf, Germany: Northrhine-Westfalia State Agency for Water and Waste. English Translation of report No. 6/93 "Phthalate in der Aquatischen Umwelt". Contract No. D/1996/3158/4. 197 p and Appendices.

Hart, L.J., S.A. Smith, B.J. Smith, J. Robertson, E.G. Besteman and S.D. Holladay. 1998. Subacute immunotoxic effects of the polycyclic aromatic hydrocarbon 7,12-dimethylbenzanthracene (DMBA) on spleen and pronephros leukocytic cell counts and phagocytic cell activity in tilapia (Oreochromis niloticus). Aquat. Toxicol., 41, 17-29.

Hironobu, W., G. Yoshiki and M. Sakai. 2003. In vitro modulation of common carp (Cyprinus carpio L.) phagocytic cells by Di-n-butyl phthalate and Di-2ethylhexyl phthalate. Aquat. Toxicol., 63, 119-126.

Jobling, S., T. Reynolds, R. White, M.G. Parker and J.P. Sumpter. 1995. A variety of environmentally persistent chemicals, including some phthalate plasticizers, are weakly estrogenic. Environ. Health. Perspect., 103, 582-587.

Kim, E.J., J.W. Kim and S.K. Lee. 2002. Inhibition of oocy te development in Japanese medaka (Oryzias latipes) exposed to di-2-ethylhexyl phthalate. Environ. Int., 28 359-365.

Menghi, G., M.G. Sabbieti, M. Menghi, A. Roda, S. Materazzi and L. Marchetti. 2002. Immunohistochemical detection of phthalate esters in the alimentary canal of Tilapia spp. J. Fish Biol., 61, 265-271.

Parkerton, T.F. and W.J. Konkel. 2000. Application of quantitative structure-activity relationships for assessing the aquatic toxicity of phthalate esters. Ecotoxicol. Environ. Safety, 45, 61-78.

Roger, A.C., B. Stacie, H. Patricia, Chang Jo, F.U. Thomas and A.H. Richard. 2002. A butyrylcholinesterase in the early development of the brine shrimp (Artemia salina) larvae: a target for phthalate esters embryotoxicity? Biochem. Biophy. Res. Commun., 299, 659662.

Sabourault, C., G. de Sousa, M. Amichot, A. Cuany, R. Rahmani, J.P. Salaun, J.B. Berge, J.P. Girard and M. Lafaurie M. 1999. Tissue-specific induction and inactivation of cytochrome $\mathrm{P} 450$ catalysing lauric acid hydroxylation in the sea bass, Dicentrarchus labrax. Comp. Biochem. Physiol. B, 122, 253-260.

Sabourault, C., J.B. Bergé, M. Lafaurie, J.P. Girard and M. Amichot. 1998. Molecular cloning of a phthalateinducible CYP4 gene (CYP4T2) in kidney from the sea bass, Dicentrarchus labrax. Biochem. Biophys. Res. Commun., 251, 213-219.

Scholz, N., R. Diefenbach, I. Rademacher and D. Linnemann. 1997. Biodegradation of DEHP, DBP, and DINP: Poorly water soluble and widely used phthalate plasticizers. Bull. Environ. Contam. Toxicol., 58, 527-534.

Shioda, T. and M. Wakabayashi. 2000. Effect of certain chemicals on the reproduction of medaka (Oryzias latipes). Chemos., 40, 239-243.

Slater, C.H., M.S. Fitzpatrick, C.B. and Schreck. 1995. Characterization of an androgen receptor in salmonid lymphocytes: possible link to androgen-induced immunosuppression. Gen. Comp. Endocrinol., 100, $218-$ 225.

Sonnenschein, C. and A.M. Soto. 1998. An updated review of environmental estrogen and androgen mimics and antagonists. J. Steroid Biochem. Molec. Biol., 65, 143-150 .

Staples, C.A., W.J. Adams, T.F. Parkerton, J.W. Gorsuch, G.R. Biddinger and K. Reinert. 1997. Aquatic Toxicity of eighteen phthalate esters: a review. Environ. Toxicol. Chem., 16, 875-891.

Sung, H.H., W.Y. Kao and Y.J. Su. 2003. Effects and toxicity of phthalate esters to hemocytes of giant freshwater prawn, Macrobrachium rosenbergii. Aquat. Toxicol., 64, 25-37. 
Tollefsen, K.E. 2002. Interaction of estrogen mimics, singly and in combination, with plasma sex steroidbinding proteins in rainbow trout (Oncorhynchus mykiss). Aquat. Toxicol., 56, 215-225.

Van den Belt, K., P. Berckmans, C. Vangenechten, R. Verheyen and H. Witters. 2004. Comparative study on the in vitro/in vivo estrogenic potencies of $17 \beta$ estradiol, estrone, $17 \alpha$-ethynylestradiol and nonylphenol. Aquat. Toxicol., 66, 183-195.

Wan-Yu, L., C. Wen-Hsiung, S. Yen-Lin, D. Sylive and C. Ching-Fong. 2001. Differential in vitro suppressive effects of steroids on leukocyte phagocytosis in two teleosts, tilapia and common carp. Gen. Comp. Endocrinol., 121, 163-172.

Yamaguchi, T., W. Hironobu and M. Sakai. 2001. Effects of estradiol, progesterone and testosterone on the function of carp, Cyprinus carpio, phagocytes in vitro. Comp. Biochem. Physiol., 129(C), 49-55.

Zacharewski, T.R., M.D. Meek, J.H. Clemons, Z.F. Wu, M.F. Fielden and J.B. Matthews. 1998. Examination of the in vitro and in vivo estrogenic activities of eight commercial phthalate esters. Toxicol. Sci., 46, 282293.

Zelikoff, J.T., A. Raymond, E. Carlson, Y. Li, J.R. Beaman and M. Anderson. 2000. Biomarkers of immunotoxicity in fish: from the lab to the ocean. Toxicol. Lett., $112 / 113,325-331$.

(Received September 2005, Accepted March 2006) 